\title{
White Matter and Disease: Does Brain have a Role in Initiating Diseases \\ Ahed J Alkhatib*
}

Department of Legal Medicine, Toxicology of Forensic Medicine, School of Medicine, Jordan University of Science and Technology, Jordan

\section{Editorial}

The brain is composed of two parts according to matter content known as gray matter and white matter. While the gray matter is composed of nerve cells, nerve fibers and myelin are the constituents of the white matter [1].

Myelin is considered a crucial part of the white matter. Alterations in the myelin sheath leads to abnormalities of impulse conduction ending with disorders in the brain functions [2].

According to the study of Lin et al. [3] the location of white matter closed to the watershed area supplied by arterial blood makes it susceptible to ischemic damage. It has been indicated that ischemia in white matter to be associated with increased uptake of oxygen [4]. Several studies have suggested that hemodynamic changes are possibly involved in white matter ischemia $[5,6]$.

Several studies reported that the lesions of white matter (WMLs) are considered as asymptomatic lesions $[7,8]$. There are two types of WMLs. The first type is deep subcortical white matter (DSWMH), while the second type is periventricular (PVH) hyper-intensities. From a clinical point of view, WMLs have the potential of escalating the risk of ischemic stroke, dementia, and death $[9,10]$. WMLs are associated with different risk factors such as age, hypertension, diabetes, chronic kidney disease, and carotid stenosis [11-13].

White matter disease plays a crucial role in modern medicine [14]. It has been associated with several diseases including stroke [15-17], vascular cognitive impairment $[17,18]$ and dementia $[19,20]$.

Recent studyby Shen et al. [21] indicated to an association between changes in the structure of white matter and depression.

From my past experience, I conducted a study and found functional alterations in white matter to play an important role in the pathology of white matter. We found that the expression of inducible nitric oxide synthase (iNOS) to have similar patterns under physiological conditions in both white matter and gray matter, but under diabetic conditions, a shift in the expression of iNOS was noted in white matter and we concluded that the expression of iNOS in white matter may explain both the progression of diabetes and the generation of diabetic neuropathies. We think that other molecular changes in white matter including decreased expression of heat shock protein (Hsp70) accompanied with increased expression of iNOS are both possibly involved in making other organs to be more likely to develop diseases [22].

Taken together, in modern medicine, much attention was given to gray matter on the account of white matter [23]. It seems that white matter disease plays important roles in developing diseases and further studies are required in both functional and structural levels. Therapeutic approaches targeting white matter may produce new treatment options for diseases.

\section{References}

1. Scholz J, Klein MC, Behrens TEJ, Johansen-BH (2009) Training induces changes in white matter architecture. Nat Neurosci 12:1370-1371.

2. Maillard P, Carmichael O, Fletcher E, Reed B, Mungas D, et al. (2012) Coevolution of white matter hyperintensities and cognition in the elderly. Neurology 79: 442-448.
3. Lin J, Wang D, Lan L, Yuhua F (2017) Multiple factors involved in the pathogenesis of white matter lesions. BioMed Res International 9372050.

4. Yao H, Sadoshima S, Ibayashi S, KuwabaraY, Ichiya Y, et al. (1992) Leukoaraiosis and dementia in hypertensive patients. Stroke 23: 1673-1677.

5. Mok V, Ding D, Fu J, Xiong Y, Chu WW, et al. (2012) Transcranial doppler ultrasound for screening cerebral small vessel disease: A community study. Stroke 43: 2791- 2793

6. Poels MM, Zaccai K, Verwoert GC, Vernooij MW, Hofman A, et al. (2012) Arterial stiffness and cerebral small vessel disease: The Rotterdam scan study. Stroke 43: 2637-2642.

7. Debette S, Markus HS (2010) The clinical importance of white matter hyperintensities on brain magnetic resonance imaging: Systematic review and meta-analysis. BMJ 341: c3666.

8. Nemoto M, Masuda H, Harada H, Sugo N, Terazono S, et al. (2017) Risk factors association with severity of white matter lesions on magnetic resonance imaging. Gen Med 5: 290.

9. Debette S1, Beiser A, DeCarli C, Au R, Himali JJ, et al. (2010). Association of MRI markers of vascular brain injury with incident stroke, mild cognitive impairment, dementia, and mortality: The Framingham offspring study. Stroke 41:600-606.

10. Zhang C, Wang Y, Zhao X, Wang C, Liu L, et al. (2014) Factors associated with severity of leukoaraiosis in first-ever lacunar stroke and atherosclerotic ischemic stroke patients. J Stroke Cerebrovasc Dis 23: 2862-2868.

11. Kandiah N, Goh O, Mak E, Marmin M, Ng A (2012) Carotid stenosis: A risk factor for cerebral white-matter disease. J Stroke Cerebrovasc Dis 23: 136-139.

12. Kuriyama N, Mizuno T, Ohshima Y, Yamada K, Ozaki E, et al. (2013) Intracranial deep white matter lesions (DWLs) are associated with chronic kidney disease (CKD) and cognitive impairment: A 5-year follow-up magnetic resonance imaging (MRI) study. Arch Gerontol Geriatr 56: 55-60.

13. Toyoda G, Bokura H, Mitaki S, Onoda K, Oguro H, et al. (2015) Association of mild kidney dysfunction with silent brain lesions in neurologically normal subjects. Cerebrovasc Dis Extra 5: 22-27.

14. Chutinet A, Rost NS (2014) White matter disease as a biomarker for long-term cerebrovascular disease and dementia. Curr Treat Options Cardiovasc Med 16: 292

15. Yamauchi H, Fukuda H, Oyanagi C (2002) Significance of white matter high intensity lesions as a predictor of stroke from arteriolosclerosis. J Neurol Neurosurg Psychiatry 72:576-582.

16. Smith EE, Gurol ME, Eng JA, Engel CR, Nguyen TN, et al. (2004) White matte lesions, cognition, and recurrent hemorrhage in lobar intracerebral hemorrhage. Neurology 63: 1606-1612.

17. Appelros P, Samuelsson M, Lindell D (2005) Lacunar infarcts: Functional and cognitive outcomes at five years in relation to MRI findings. Cerebrovasc Dis 20:34-40.

18. Smith EE, Egorova S, Blacker D, Killiany RJ, Muzikansky A, et al. (2008)

*Corresponding author: Ahed J Alkhatib, Department of Legal Medicine Toxicology of Forensic Medicine, School of Medicine, Jordan University of Science and Technology, Jordan, Tel: 96227201000; E-mail: drahedalkatib@yahoo.com

Received September 15, 2017; Accepted October 24, 2017; Published October 30 2017

Citation: Alkhatib AJ (2017) White Matter and Disease: Does Brain have a Role in Initiating Diseases. Brain Disord Ther 6: e124. doi: 10.4172/2168-975X.1000e124

Copyright: @ 2017 Alkhatib AJ. This is an open-access article distributed under the terms of the Creative Commons Attribution License, which permits unrestricted use, distribution, and reproduction in any medium, provided the original author and source are credited. 
Citation: Alkhatib AJ (2017) White Matter and Disease: Does Brain have a Role in Initiating Diseases. Brain Disord Ther 6: e124. doi: 10.4172/2168-975X.1000e124

Page 2 of 2

Magnetic resonance imaging white matter hyperintensities and brain volume in the prediction of mild cognitive impairment and dementia. Arch Neurol 65:94-100.

19. Prins ND, Van Dijk EJ, Den Heijer T, Vermeer SE, Koudstaal PJ, et al (2004) Cerebral white matter lesions and the risk of dementia. Arch Neurol 61:1531-1534.

20. Meguro K1, Ishii H, Kasuya M, Akanuma K, Meguro M, et al. (2007) Incidence of dementia and associated risk factors in Japan: The Osaki-Tajiri project. J Neurol Sci. 260:175-182.
21. Shen X, Lianne MR, Simon RC, Mark JA, David CL, et al. (2017) Subcortical volume and white matter integrity abnormalities in major depressive disorder: findings from UK Biobank imaging data. Scientific Reports 7: 5547.

22. Al-khatib AJ (2013) Co-expression of iNOS and HSP70 in diabetes type 1 makes a rational hypothesis to explain the d Mok iabetic neuropathy. Eur Scientific J 9: 145-56

23. Douglas Fields $R$ (2010) Change in the brain's white matter: The role of the brain's white matter in active learning and memory may be underestimated Science 330: 768-769. 